\title{
Shelf life assessment of Malaysian Pangasius sutchi during cold storage
}

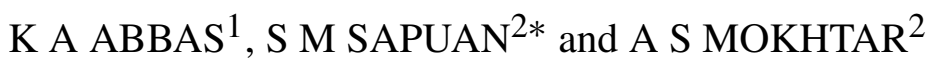 \\ ${ }^{1}$ Faculty of Food Science \& Technology, and ${ }^{2}$ Faculty of Engineering Universiti \\ Putra Malaysia, 43400 Serdang, Selangor, Malaysia \\ e-mail: drsapuan@yahoo.com
}

MS received 10 September 2005; revised 10 April 2006

\begin{abstract}
The findings of the present work yield useful information about the Malaysian Pangasius sutchi concerning the marketing sector from the point of view of shelf life and storage temperature in the range of 0 to $10^{\circ} \mathrm{C}$. A fresh batch of typical samples, were stored similarly in four chillers of different temperatures for a period of 28 days. During the course of storage, the samples were periodically subjected to $\mathrm{pH}$ and sensory tests performed by trained panelists. Experimental observations were analysed and regressed to develop three correlations. The first one was between the sensory tests and the storage time and temperatures, while the second one related $\mathrm{pH}$ values to storage time and temperatures. Finally, a correlation between sensorial and $\mathrm{pH}$ values was developed as well. The first correlation is presented in tabular form to yield a simple guide to fish retailers, by which quality and shelf life of the displayed fish commodity may be estimated.
\end{abstract}

Keywords. Freshwater fish; cold storage; shelf life.

\section{Introduction}

Patin (Pangasius sutchi) is a popular freshwater fish used as food in Malaysia (Mohsin \& Ambak 1983; Fisheries Dept. 2000). This fish species is also abundantly available in the Amazon River, in parts of Russia and in other places of the world under different names. In Bangladesh, Indonesia (Borneo and Java), India and Thailand, it has the same name, i.e. Patin (Fisheries Dept. 2000). This species prefers the deep dark pools of large rivers and lives on a diet of vegetable matter, worms, various grubs, carrion, small fish and freshwater prawns (Aznir 1998). The environment in which they are grown influences the properties of the fish. Due to this reason, differences in the composition of Patin fish are expected from country to country which eventually results in differences in shelf-life for fish from various countries. A data bank on the quality characteristics of the fish species of a particular location would be useful for marketing.

Shelf life of a fish species is the time from when it is taken from the water until it is no longer fit to eat. Shelf lives of fresh and frozen fish are very important criteria for marketing. The remaining shelf life allows a processor or a retailer to plan the length of time a product can be 
held, allowing control of the market. Adding one or two days to the shelf life allows the market to get good profitability and assure repeat sales. Temperature and handling practices are the most important factors in determining the shelf life of all species of fish. If a fish product is handled carefully, the temperature at which it is held controls its useful life. Temperature controls the rate of bacterial spoilage and enzyme breakdown. An indisputable fact is that the higher the temperatures the faster fish get spoilt (Connell 1990)

Fish consumption in Malaysia has increased dramatically in the past 10 years (Fisheries Dept. 2000). consumers have become more aware of the benefits of eating fish and of consuming fish of high quality. While consumption has increased, the Malaysian fisheries industry needs to meet this competition directly by improving quality and by marketing more fresh product. Freshwater fish was found to be a viable resource to meet the demand in the market. Karim (1990) reported that the Malaysian Fisheries Department is now encouraging and expanding freshwater fish-rearing industry among agriculturists and fishermen to increase their income. Fish farming techniques are improving with the introduction of new techniques in order to have consistent supply of freshwater fish throughout the year.

Recent marketing studies have indicated that consumers of seafood preferred fresh fish to frozen (Evans Kraft 1988). Accordingly, most fish-sellers prefer to display this commodity in chillers in the range of 0 to $10^{\circ} \mathrm{C}$ to attract customers.

Further research is needed to enhance the consumption and utilization of Malaysian patin and also to analyse the quality characteristics of this species during cold storage. Due to the scarcity of such information (H A Hasimah - personal communication; Ansari et al 2003, 2004; Sapuan et al 2003; Abbas et al 2005) and since a simple tool which delivers expected shelf life is still not available to sellers, this kind of research work is necessary and justified.

\section{Materials and methods}

\subsection{Materials}

Pangasius sutchi, which is known locally as Patin species of local freshwater fish (Aznir 1998), is chosen as the sample. Pangasius sutchi fish were bought from a nearby farm. The fish were brought alive to the fish laboratory in batches, and were chosen according to their normal market sizes, their weight and length being recorded before filleting was done. Due to non-homogeneity in the flesh of the fish over the entire body, the sampling area was selected from the upper portion with respect to the lateral line of the fish body as shown in figure 1 .

\subsection{Methods}

2.2a Sample preparations: Prior to filleting, the fish were killed by stunning the head with a metal rod for fast death. The fillets were taken from about $5 \mathrm{~cm}$ below the operculum up to about $10 \mathrm{~cm}$ from the tail end. This was followed by deskinning. Filleting and deskinning

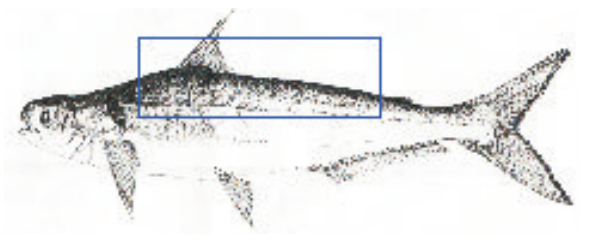

Figure 1. The selected area for sampling. 
Table 1. Sensory evaluation score by panelists.

\begin{tabular}{cl}
\hline Score & Overall acceptance \\
\hline 1 & Liked very much \\
2 & Liked moderately \\
3 & Liked slightly \\
4 & Neither liked or disliked \\
5 & Disliked slightly \\
6 & Disliked moderately \\
7 & Disliked very much \\
\hline
\end{tabular}

were both done manually. Fillets were kept in styrofoam boxes containing crushed ice while waiting for all fish in the batch to be filleted and deskinned. The fillets were then washed under running tap water to remove blood, dirt and slime, weighed and divided into four lots. The first lot was used for storage study at $0^{\circ} \mathrm{C}$ and the second, third and fourth lots at $3^{\circ}, 5^{\circ}$, and $10^{\circ} \mathrm{C}$ respectively.

2.2b pH measurement: Fish muscle was blended in a Waring blender with 1 part of muscle to 5 parts of distilled water. The $\mathrm{pH}$ was read directly from a laboratory $\mathrm{pH}$ meter (Hanna Instrument, 471, Italy-made). Determination was done as 3 replicates.

2.2c Sensory evaluation: Sensory evaluation was performed by a trained panel of 10 members drawn from the Faculty of Food Science and Technology, Universiti Putra Malaysia (Woyeda et al 1986). Panelists were asked to evaluate the overall acceptance of the thawed fillets cut in to about $4 \mathrm{~cm}$ length and $1 \mathrm{~cm}$ thick pieces. The evaluation used was based on a scale of 7 points. Table 1 lists sensory evaluation scores for the overall acceptability according to each panelist's judgment.

It is notable that shelf life cannot be assessed without sensory evaluation. Based on the above table scores, shelf life could be defined as the time needed for the stored sample to reach the score value of 7 .

\section{Results and discussion}

\subsection{Changes in $p H$ values}

The initial $\mathrm{pH}$ values of the fresh samples were measured to be 6.03. A significant increase in $\mathrm{pH}$ of the four batches during storage course has been noted. All the batches exhibit similar increasing behaviour. However, each batch yielded different $\mathrm{pH}$ value in the end of the storage period according to the storage temperature of that chiller. Figure 2 revealed that $6 \cdot 8,6 \cdot 96,7 \cdot 12$, and $7 \cdot 6$ are the end $\mathrm{pH}$ values of the storage temperatures $0^{\circ}, 3^{\circ}, 5^{\circ}$ and $10^{\circ} \mathrm{C}$ respectively.

Observations of $\mathrm{pH}$ values along with those of time and temperature of preservation were regressed to obtain a correlation by which an estimate of $\mathrm{pH}$ value at any prescribed storage (chilling) temperature and storage time could be predicted without using the $\mathrm{pH}$ meter.

The MMF model was found to deliver satisfactory fitting as follows:

$$
p H=\left(a b+c D^{d}\right) /\left(b+D^{d}\right) .
$$




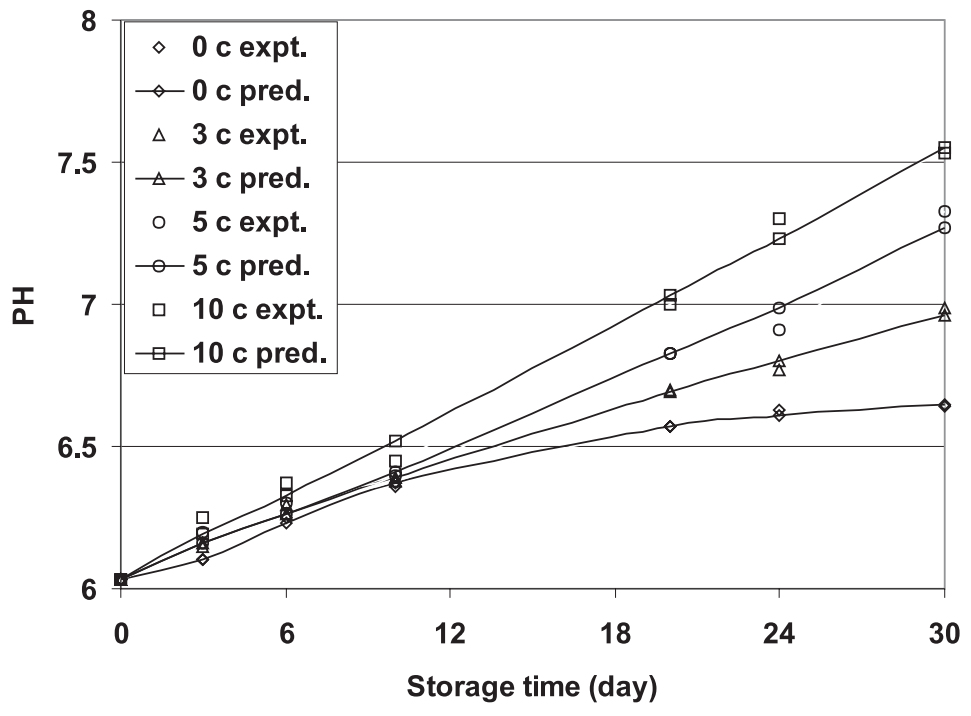

Figure 2. Evolution of $\mathrm{pH}$ value during storage period.

Constants $a, b, c$, and $d$ are functions of storage temperature, therefore for the purpose of precise estimation the following equations may be used along with the storage temperature.

$$
\begin{aligned}
a & =1 /\left(0.166-0.00031 T+1.89633 E-5 T^{2}\right), \\
b & =1514948.9 \exp \left[-(4.7-T)^{2} / 0.529\right], \\
c & =[125.44-5.67 T] /\left[1-0.1357 T-0.0127 T^{2}\right], \\
d & =[1.645+9.45 E 9 T] /\left[1+1.011 E 10-1.587 E 8 T^{2}\right] .
\end{aligned}
$$

Earlier, Gould \& Peters (1971) associated the increase in pH during storage of fish muscle with depletion of tissues. They also reported measurement of the $\mathrm{pH}$ of surface flesh as a rapid test for detection of spoilage at sea. However, they neither mentioned the exact cause of spoilage nor the acceptable range of $\mathrm{pH}$. Jamilah \& Mohd (1993) also reported the increase in $\mathrm{pH}$ during their study of bighead carp kept at ambient temperature. Love (1983) and Rhee et al (1984) reported that enzyme-catalysed oxidation in fish muscle tissue reached the optimum rate at $\mathrm{pH} 6.5$. This implies that enzyme-catalysed oxidation is at its peak at $\mathrm{pH} 6.5$. The activity still goes on thereafter, though at a lower rate.

\subsection{Sensory evaluation}

Spoilage and quality deterioration can be assessed by chemical and physical methods and sensory evaluation (Connell 1990). Not all chemical assessments give good correlation to quality changes, hence sensory evaluation is a necessity (Hardy 1979). Ismail (2000) reported that the necessity of conducting sensory evaluation. Sensory testing plays an important role in food quality evaluation since the ultimate test of food quality is consumer response. Instrumental methods to determine some physical, chemical or biological properties of food have been developed and are being used to assess flavour, colour and texture. However, sensory 


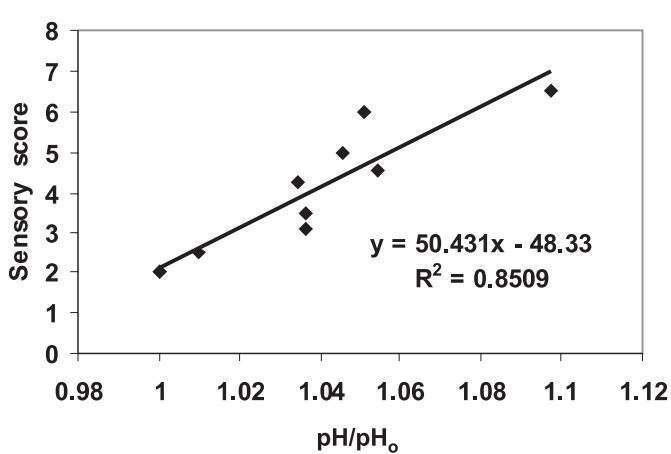

Figure 3. Relationship between acceptability and $\mathrm{pH}$ ratio.

evaluation panels must be used to ensure that instrumental methods are properly correlated with sensory data.

In general, sensory evaluations were carried out for all samples kept at different temperatures. The results were then evaluated using the hedonic scale. These sensory evaluations have been correlated with the $\mathrm{pH} / \mathrm{pH}_{0}$ variation to yield the following relationship, as shown in figure 3 (acc = acceptability)

$$
\text { acc }=-48 \cdot 331307+50 \cdot 431848\left(\mathrm{pH} / \mathrm{pH}_{0}\right) .
$$

For samples kept at $0^{\circ} \mathrm{C}$, in order to correlate the storage time with the $\mathrm{pH} / \mathrm{pH}_{0}$, the following fourth-degree polynomial with standard error 0.0092364 and correlation coefficient 0.9791578 has been suggested satisfactorily as shown in figure 4 .

$$
\begin{aligned}
\left(\mathrm{pH} / \mathrm{pH}_{0}\right)= & 0.00+0.00139 D+0.00152 D^{2}-0.000187 D^{3} \\
& +6.355 \times 10^{-6} D^{4} .
\end{aligned}
$$

Equations (6) and (7) make it possible to predict the sensory evaluation of the samples kept at $0^{\circ} \mathrm{C}$.

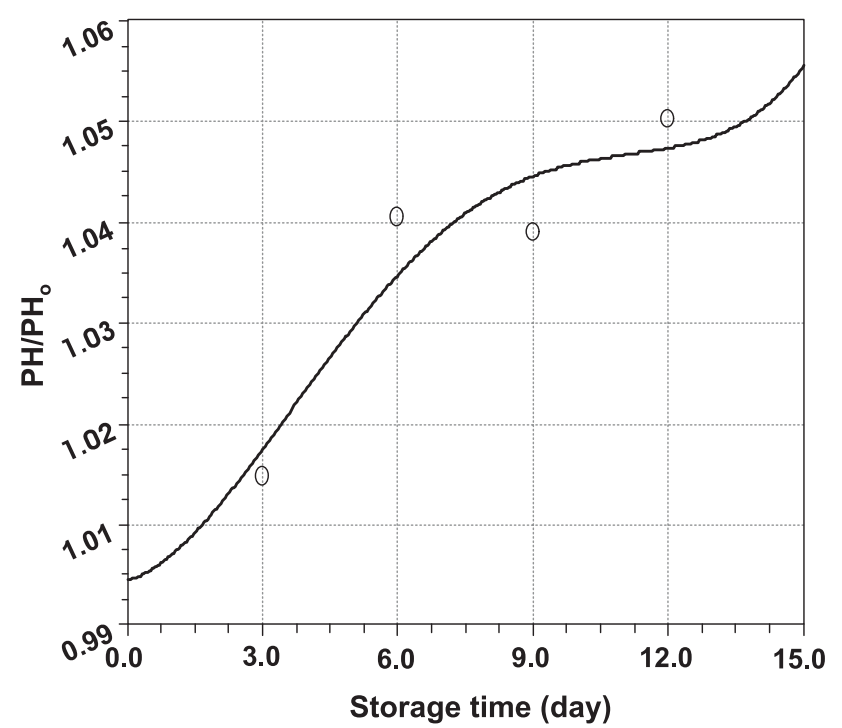

Figure 4. Variation of $\mathrm{pH}$ ratio during storage. 


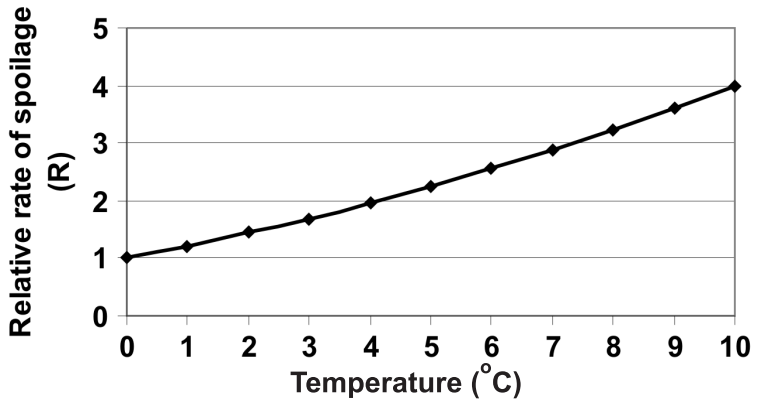

Figure 5. Effect of storage temperature on spoilage.

Knowledge of the relative rates of spoilage at different storage temperatures are often useful when estimating the quality of fish of known temperature history, although, as indicated earlier, this applies only to fish kept above $0^{\circ} \mathrm{C}$. Since ice melts at $0^{\circ} \mathrm{C}$ under normal conditions, a reference temperature of $0^{\circ} \mathrm{C}$ is normally used when comparing storage times for fresh fish and shellfish. An extrapolation from the Arrhenius reaction rate equation allows the calculation of 'relative spoilage rates' of fish and shellfish for temperatures above $0^{\circ} \mathrm{C}$ Gorga $\&$ Rousivalli 1988. The relative spoilage rate $(R)$ is given by

$$
R=\left(1+0 \cdot 1 T_{\text {chilling }}\right)^{2} .
$$

This gives an indication of the quality of the fish by assuming that the fish is in prime condition when caught, and that handling is of a sufficiently high standard to avoid problems such as bruising. Poor handling would result in much more rapid spoilage than the calculated equivalent 'length of time on ice' would indicate. Figure 5 depicts the relationship between the relative rate of spoilage and storage temperatures used in this study. Equation (1) was utilized to calculate $\mathrm{pH} / \mathrm{pH}_{0}$ every day during the course of storage, and the sensory evaluation score were deduced via (6). Since (8) has been explained already to predict the relative rate of spoilage for storage temperature other than $0^{\circ} \mathrm{C}$. According to this it may be inferred that it is possible to predict the sensory evaluation score for other storage temperatures as shown in table 2. In this table, the relationship between the hedonic score with time and temperature of storage is described numerically. The time corresponds to the sensory score of 7 which is the shelf life. Therefore, such marginal values are highlighted to remind the reader of the shelf life under that storage temperature.

Samples kept at higher temperature exhibit a shorter shelf life as compared to samples kept at $0^{\circ} \mathrm{C}$. The results of table 2 were regressed to represent the relationship between the shelf life and the storage temperature (figure 6). With a standard error of 0.6970091 and a correlation coefficient of 0.9957484 the Harris model was found to be the most suitable one to represent that relationship mathematically in the following equation:

$$
S=1\left(0 \cdot 056+0 \cdot 0006 T^{3 \cdot 27}\right) .
$$

\section{Conclusion}

The work presented above reveals that all cold-stored samples under various temperatures are subject to increasing in $\mathrm{pH}$ and sensory score values. The higher the storage temperature 


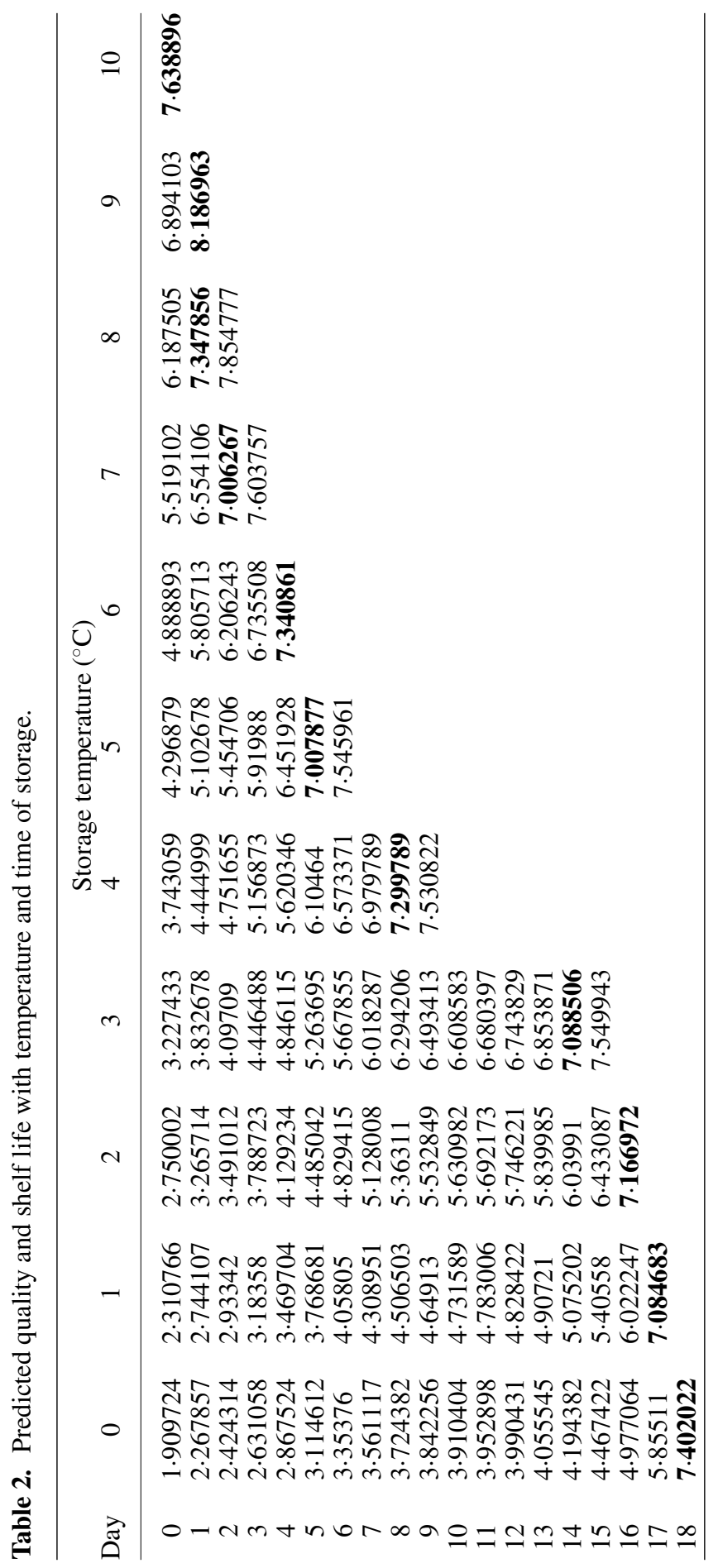




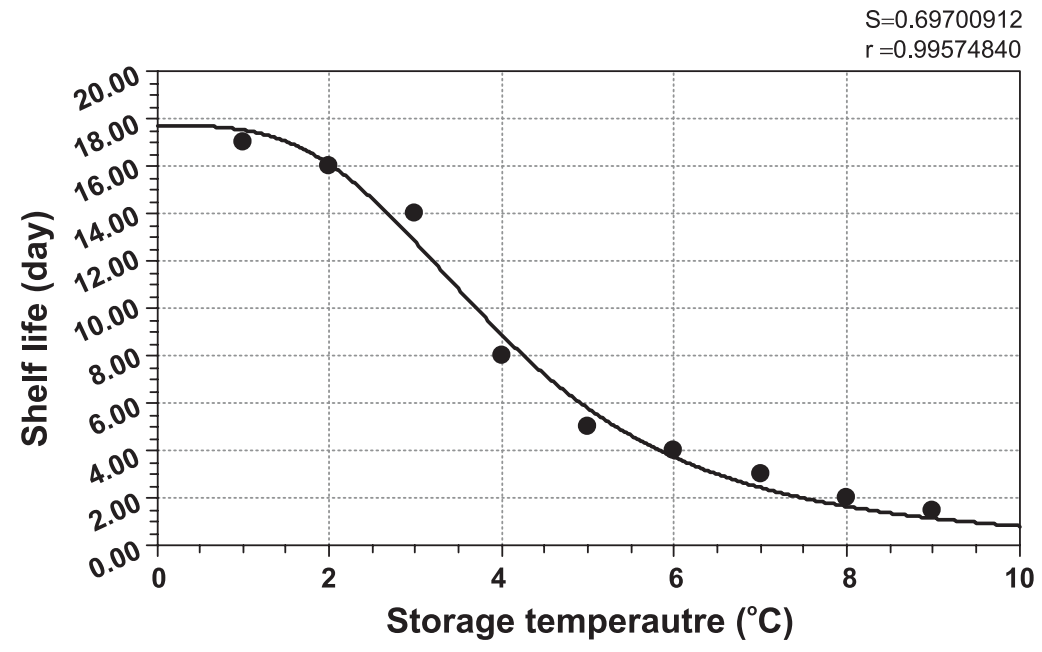

Figure 6. Relationship of shelf life with storage temperature.

the faster is the increase in these values. Two correlations describing the variation of $\mathrm{pH}$ and sensory score during storage have been developed. Since each correlation is a function of time and temperature of storage, this had lead the authors to develop another relationship between sensory score and $\mathrm{pH} / \mathrm{pH}_{0}$ via (7) and (8). This relationship is presented in tabular form in table 2 . The table represents a simple tool by which quality deterioration and shelf life of the stored fish may be predicted in the fish marketing sector.

\section{List of symbols}

$a, b, c, d \quad$ polynomial coefficients;

acc Hedonic score;

$D \quad$ the storage time (day);

pH acidity index;

$S \quad$ shelf life (day);

$T \quad$ storage temperature $\left({ }^{\circ} \mathrm{C}\right)$;

Subscript

$0 \quad$ fresh

\section{References}

Abbas K A, Sapuan S M, Ahmad M M H M, Mokhtar A S, Jamilah B 2005 Determination of thermal conductivity of Malaysian patin fish. J. Food. Agric. Environ. 3: 44-48

Ansari F A, Abbas M, Hamdan M, Ashraf O A, Mahdi E, Bakar J, Sapuan S M, Wan M A 2003 Thermal diffusivity investigation of fresh water patin fish during cold preservation. Proc. 2nd Int. Conf. on Heat Transfer, Fluid Mechanics and Thermodynamics (Victoria Falls, Zambia: Univ. of Zambia) Paper number:AF1-5

Ansari F A, Abbas K A, Ahmad M M H 2004 A correlation between thermal diffusivity variation and quality of cold preserved fish. ASEAN J. Sci. Technol. Dev. 21: 1-10 
Aznir M 1998 Patin. Rod Line (31): 54-56

Connell J J 1990 Control of fish quality 3rd edn (Oxford: Fishing News Books)

Evans Kraft 1988 Company Report to the Alaska Seafood Marketing Institute on a Survey of Consumer Preferences in Seafood Seattle, WA, USA

Fisheries Dept. 2000 Malaysian Fisheries Department, Official Homepage http://agrolink.moa.my/dof/stats

Gorga C, Rousivalli L J 1988 Quality assurance of seafood (Westport, CT: AVI)

Gould E, Peters A J 1971 On letting the freshness of frozen fish (Oxford: Fishing News Book)

Hardy R 1979 Fish lipids. Part 2. In Advances in fish science and technology (ed.) J J Connell (Oxford: Fishing News Books)

Ismail M I 2000 Lipid oxidation in some of Malaysian freshwater fish. B Sc thesis, Faculty of Food Science and Biotechnology, Universiti Putra Malaysia Serdang, Selangor, Malaysia

Jamilah B, Mohd A Y 1993 Changes in bighead carp (A. nolbilis\} stored at ambient temperature. ASEAN Food J. 8: 149-152

Karim G 1990 Information Malaysia 1990-1993, Year Book (Kuala Lumpur: Berita)

Love J D 1983 The role of hemi iron in the oxidation of lipids in red meat. J. Food Technol. 37: 117-123

Mohsin A K M, Ambak A A M 1983 Freshwater fishes of Peninsular Malaysia (Serdang, Selangor: Universiti Pertanian Malaysia Press)

Rhee K S, Dutson T R, Smith G C 1984 Enzymic lipid peroxidation in microsomal fractions from beef skeletal muscle. J. Food Sci. 49: 675-689

Sapuan S M, Mokhtar A S, Abbas K A, Jamilah B, Ashraf A O, Hamdan M, Wan M A, Abas F 2003 Comparative study in thermal diffusivity measurement methods stability of Malaysian Pangasius sutchi. J. Energy Heat Mass Transfer 25: 217-230

Woyeda A D, Shaw S, Burns B G 1986 Recommended methods for assessment of fish quality. Canadian Technical Report of Fisheries and Aquatic Sciences. No. 1448, Halifax, Canada 